\title{
Irreversible accumulated SERS behavior of the molecule-linked silver and silver-doped titanium dioxide hybrid system
}

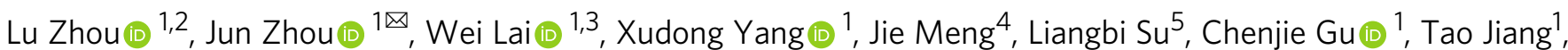
Edwin Yue Bun Pun ${ }^{6}$, Liyang Shao (1) ${ }^{7}$, Lucia Petti ${ }^{8}$, Xiao Wei Sun (1) ${ }^{7}$, Zhenghong Jia9 ${ }^{9}$ Qunxiang Li ${ }^{4}$, Jiaguang Han (I) $^{2}$ \& Pasquale Mormile ${ }^{8}$

In recent years, surface-enhanced Raman scattering (SERS) of a molecule/metal-semiconductor hybrid system has attracted considerable interest and regarded as the synergetic contribution of the electromagnetic and chemical enhancements from the incorporation of noble metal into semiconductor nanomaterials. However, the underlying mechanism is still to be revealed in detail. Herein, we report an irreversible accumulated SERS behavior induced by near-infrared (NIR) light irradiating on a 4-mercaptobenzoic acid linked with silver and silver-doped titanium dioxide (4MBA/Ag/Ag-doped $\mathrm{TiO}_{2}$ ) hybrid system. With increasing irradiation time, the SERS intensity of $4 \mathrm{MBA}$ shows an irreversible exponential increase, and the Raman signal of the $\mathrm{Ag} / \mathrm{Ag}$-doped $\mathrm{TiO}_{2}$ substrate displays an exponential decrease. A microscopic understanding of the time-dependent SERS behavior is derived based on the microanalysis of the $\mathrm{Ag} / \mathrm{Ag}$-doped $\mathrm{TiO}_{2}$ nanostructure and the molecular dynamics, which is attributed to three factors: (1) higher crystallinity of $\mathrm{Ag} / \mathrm{Ag}$-doped $\mathrm{TiO}_{2}$ substrate; (2) photo-induced charge transfer; (3) chargeinduced molecular reorientation.

\footnotetext{
${ }^{1}$ Department of Microelectronic Science and Engineering, School of Physical Science and Technology, Ningbo University, Ningbo 315211, China. ${ }^{2}$ Center for Terahertz Waves and College of Precision Instrument and Optoelectronics Engineering, Tianjin University, Tianjin 300072, China. ${ }^{3}$ Shanghai Key Laboratory of Green Chemistry and Chemical Processes, School of Chemistry and Molecular Engineering, East China Normal University, Shanghai 200241, China. ${ }^{4}$ Hefei National Laboratory for Physical Sciences at the Microscale, and Synergetic Innovation Center of Quantum Information and Quantum Physics, University of Science and Technology of China, Hefei 230026, China. ${ }^{5}$ Key Laboratory of Transparent and Opto-functional Inorganic Materials, Shanghai Institute of Ceramics, Chinese Academy of Sciences, Shanghai 201800, China. ${ }^{6}$ Department of Electrical Engineering and State Key Laboratory of Terahertz and Millimeter Waves, City University of Hong Kong, 83 Tat Chee Avenue, Kowloon Tong, Hong Kong, China. ${ }^{7}$ Department of Electrical and Electronic Engineering, Southern University of Science and Technology, Shenzhen 518055, China. ${ }^{8}$ Institute of Applied Sciences and Intelligent Systems-ISASI, CNR, Via Campi Flegrei, 34, 80078 Pozzuoli, Napoli, Italy. ${ }^{9}$ School of Information Science and Engineering, Xinjiang University, Urumai 830046 Xinjiang, China.

凶email: zhoujun@nbu.edu.cn
} 
S urface-enhanced Raman scattering (SERS) has been intensive studied since it was first observed by a roughened silver electrode decorated by pyridine ${ }^{1}$. Due to its high sensitivity and selectivity on the designated analyte adsorbed on the noble metal and/or semiconductor substrates, SERS has been used as a powerful and useful tool for fingerprint tracing of biological and chemical molecules, such as tumor markers ${ }^{2}$, extracellular metabolites $^{3}$, and pesticide residues ${ }^{4}$, even explosives ${ }^{5}$. And it is widely accepted that the electromagnetic enhancement (EE) and the chemical enhancement (CE) are two main mechanisms to contribute the SERS ${ }^{6,7}$. In generally, EE is considered to be the dominated factor for SERS and is derived from the localized surface plasmon resonance in noble metal nanostructure ${ }^{8,9}$. As for $\mathrm{CE}$, a clear picture is still in debate, and one of the popular explanations is attributed to the charge transfer (CT) between the substrate and adsorbate ${ }^{10-12}$. Empirical evidence shows that SERS produced by $\mathrm{CT}$ is usually weak, comparing with that of $\mathrm{EE}^{13}$. However, in terms of CE, the high SERS enhanced factor (EF) has been measured recently for the molecule adsorbed on the metal-oxide semiconductor substrates fabricated through various defect engineering ${ }^{14-17}$. It has been suggested that the SERS enhancement is owing to the CT increased by Herzberg-Teller coupling, which provides a profound understanding on the defect-assisted $C E^{18,19}$. Moreover, the additional studies have been carried out to investigate the SERS enhancement from the hybrid system composed of noble metal nanostructure and metal-oxide semiconductor ${ }^{20,21}$. Guo et al. fabricated of $\mathrm{Au}-\mathrm{Cu}_{2} \mathrm{O} / \mathrm{rGO}$ nanocomposites as efficient SERS substrate which origin from the synergistic effect of $\mathrm{CE}$ and $\mathrm{EE}^{22}$. Liu et al. prepared flower-shaped $\mathrm{Au}-\mathrm{ZnO}$ hybrid nanoparticles with strong charge-transfer-induced SERS property and used as biocompatible and recyclable SERS-active substrate ${ }^{23}$. Zhao's group reported SERS response of adsorbed molecules on $\mathrm{TiO}_{2}$ nanoparticles and proposed the enhanced Raman scattering can be attributed to the plasmon resonance absorption of $\mathrm{Ag}$ and the CT of $\mathrm{TiO}_{2}$-to-molecule ${ }^{24,25}$. Further, a recent development made by Parkin' group focused on a photo-induced SERS enhancement in two steps: UV pre-irradiating of $\mathrm{Au} / \mathrm{TiO}_{2}$ substrate to create oxygen vacancy $\left(\mathrm{V}_{\mathrm{O}}\right)$ defects for facilizing of CT between the molecule and substrate to induce an intense SERS signal upon Raman laser illumination ${ }^{26}$. The above studies have provided a profound understanding of CE based on the defect-assisted CT, however, as for the SERS of the hybrid system composed of noble metal and metal-oxide semiconductor under irradiation of near-infrared (NIR) light, the dynamic processes of the $\mathrm{V}_{\mathrm{O}}$ defects and the adsorbed molecule have not been analyzed in detail, preventing of reveal the more mechanism behind SERS.

Factually, earlier studies also indicate that the orientation of the analyte on the substrate would affect the SERS signal intensity. For example, the orientation-dependent Raman response of the pMA molecule on $\mathrm{Au}$ bowtie nano-antenna system were explored $^{27}$. In this pioneering study, certain “on/off” intensities fluctuations in SERS spectra of $p M A$ were observed and explained into the reorientation of $p \mathrm{MA}$ molecule located at a defect site from vertical to horizontal on the surface of the metal by a lightinduced dynamic CT process. Similar work was also carried out for the folic acid on Au and Ag substrate, and the significant increase of SERS signal was caused by reorientation of folic acid molecules towards silver surface at high temperature and this change would persist even after the Ag substrate was cooled down to room temperature ${ }^{28}$. Recently, the impact of the temperature as well as $\mathrm{pH}$ environment on molecular orientation were also investigated $^{29}$, but there are limited theoretical analysis as well as the mechanism exploration for their molecular dynamic picture.

In this work, using an $\mathrm{Ag} / \mathrm{Ag}$-doped $\mathrm{TiO}_{2}$ nanostructure as substrate and coating with 4-mercaptobenzoic acid (4MBA), the SERS signals of $4 \mathrm{MBA}$ and the Raman signals of the Ag/Agdoped $\mathrm{TiO}_{2}$ substrate are observed to be exponentially and irreversibly change with increase of irradiation time of the NIR light (785-nm wavelength). Based on the above observations, the synergistic effect between the $\mathrm{CE}$ of $\mathrm{TiO}_{2}$-to-molecule $\mathrm{CT}$ and the $\mathrm{EE}$ of $\mathrm{Ag}$ nanoparticle ( $\mathrm{Ag} \mathrm{NPs}$ ) is responsible for the timedependent SERS behavior of the molecule/metal-semiconductor hybrid system. Further, three microscopic physical mechanisms are proposed and visualized in Fig. 1, which includes the higher crystallinity of the $\mathrm{Ag} / \mathrm{Ag}$-doped $\mathrm{TiO}_{2}$ substrate, photo-induced CT and charge-induced molecular reorientation in a localized electromagnetic field. The given microscopic picture shows more comprehensive understanding of the underlying mechanisms of the above SERS phenomenon, and helps to construct a functional metal-semiconductor substrate with excellent SERS performance, thus opening further applications.

\section{Results}

Substrate characterizations. The Ag/Ag-doped $\mathrm{TiO}_{2}$ substrate was synthesized by modified sol-hydrothermal method with the assistance of $\mathrm{NaOH}$ additive ${ }^{30}$. The morphology of the prepared

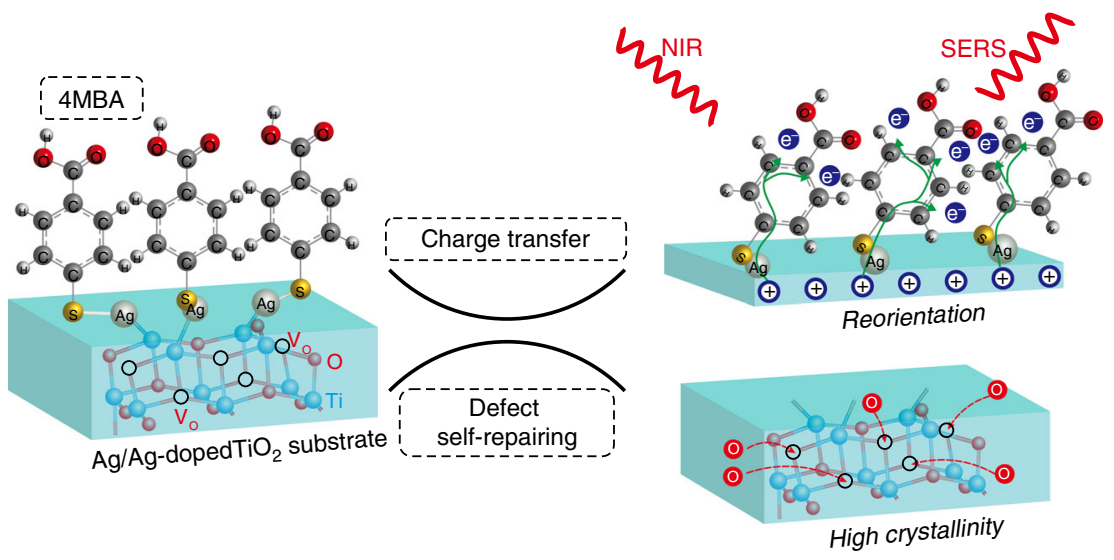

Fig. 1 NIR light-induced irreversible accumulated SERS behavior of the $\mathbf{4 M B A} / \mathbf{A g} / \mathbf{A g}$-doped $\mathbf{T i O}_{\mathbf{2}}$ hybrid system. Three mechanisms are proposed to explain this phenomenon: (1) NIR light induces a thermal effect on the substrate, which results in higher crystallinity to change polarizability; (2) NIR light induces $\mathrm{CT}$ between the substrate and $4 \mathrm{MBA}$ with the assistance of $\mathrm{V}_{\mathrm{O}}$ defects; (3) the electrostatic attraction causes the reorientation of $4 \mathrm{MBA}$ molecule on the surface of the $\mathrm{Ag} / \mathrm{Ag}$-doped $\mathrm{TiO}_{2}$ substrate. Here, the green arrows represent the transfer path of electrons between the $\mathrm{Ag} / \mathrm{Ag}$-doped $\mathrm{TiO}{ }_{2}$ substrate and $4 \mathrm{MBA}$ molecules, and the red arrows display filling of $\mathrm{V}_{\mathrm{O}}$ defect by oxygen atoms. 

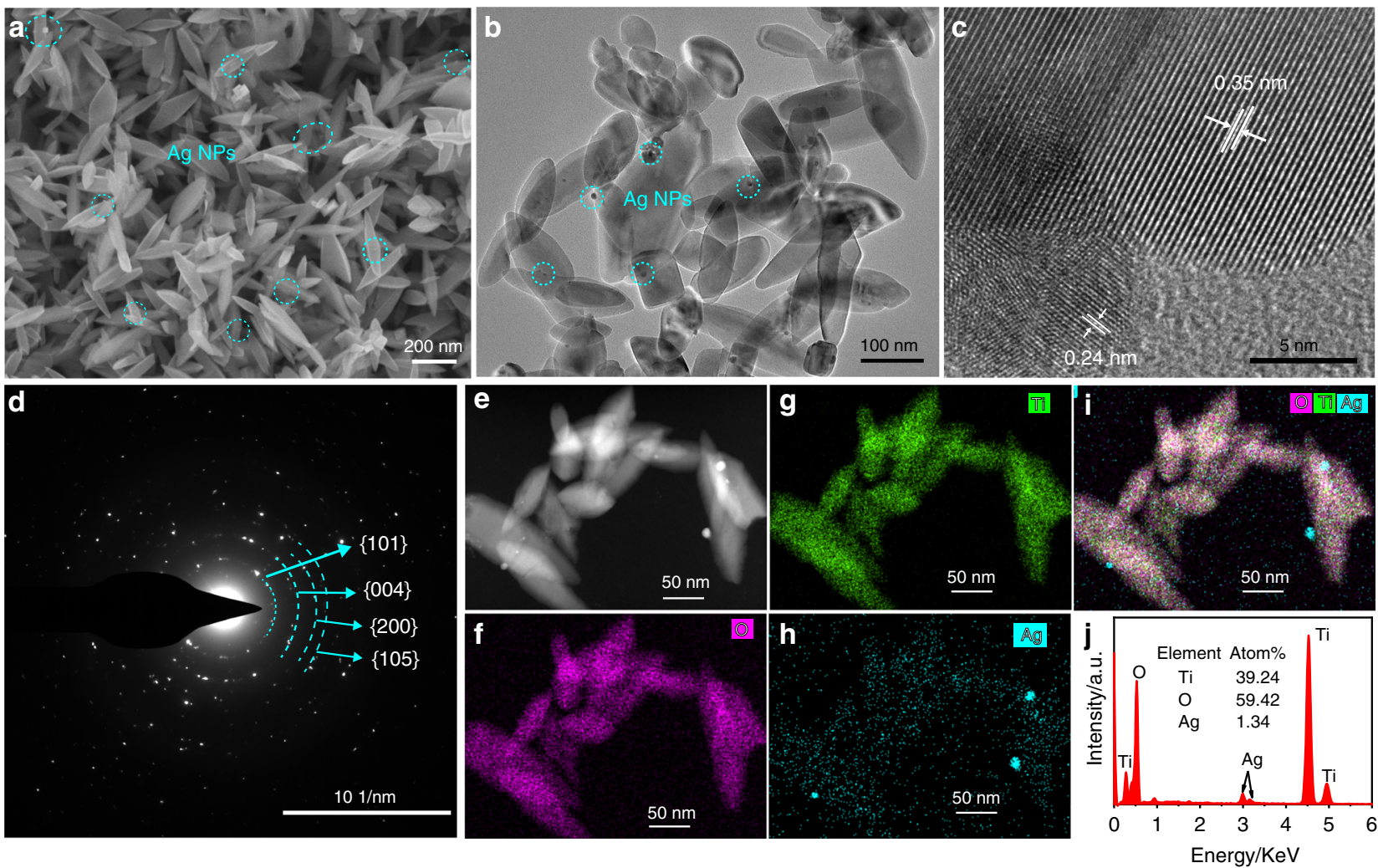

Fig. 2 Characterizations of the $\mathbf{A g} / \mathbf{A g}$-doped $\mathrm{TiO}_{\mathbf{2}}$ substrate. a SEM and $\mathbf{b} \mathrm{TEM}$ images of the $\mathrm{Ag} / \mathrm{Ag}$-doped $\mathrm{TiO}_{2}$ nanostructure prepared with $0.5 \mathrm{mM}$ of $\mathrm{AgNO}_{3}, \mathrm{Ag} \mathrm{NPs}$ were marked by circles; $\mathbf{c}$ HRTEM image of single $\mathrm{Ag} / \mathrm{Ag}$-doped $\mathrm{TiO}_{2}$ nanostructure, showing clear lattice fringe with a spacing of 0.35 and $0.24 \mathrm{~nm}$; d SAED pattern of the $\mathrm{Ag} / \mathrm{Ag}$-doped $\mathrm{TiO}_{2}$ nanostructure, mainly exhibits the (101), (004), (200), and (105) crystal facets of the anatase phase $\mathrm{TiO}_{2}$. e High-angle annular dark field image and local element mappings of (f) O, (g) Ti, (h) Ag, and (i) the overlay distribution of elements; (j) EDS spectrum.

sample with $0.5 \mathrm{mM} \mathrm{AgNO}_{3}$ is characterized by scanning electron microscope (SEM) and transmission electron microscope (TEM), and is shown in Fig. 2a, b. It can be seen that the nanostructure piling on the substrate shows an elliptical rod shape with a size of $\sim 200 \mathrm{~nm}$ and a few of Ag NPs. The high-resolution transmission electron microscope (HRTEM) image of the Ag/Ag-doped $\mathrm{TiO}_{2}$ nanostructure (Fig. 2c) displays clear lattice fringes with interplanar spacing of 0.35 and $0.24 \mathrm{~nm}$, which correspond to the anatase $\mathrm{TiO}_{2}$ (101) plane and the $\mathrm{Ag}$ (111) plane, respectively. In the selective area electron diffraction (SAED) pattern (Fig. 2d), the $\mathrm{Ag} / \mathrm{Ag}$-doped $\mathrm{TiO}_{2}$ nanostructure was further confirmed to be polycrystal structure with (101), (004), (200), and (105) concentric diffraction rings of anatase $\mathrm{TiO}_{2}$. The local elemental mappings of the $\mathrm{Ag} / \mathrm{Ag}$-doped $\mathrm{TiO}_{2}$ nanostructure are shown in Fig. $2 \mathrm{e}-\mathrm{i}$ and clearly display the $\mathrm{Ag}$, $\mathrm{Ti}$, and $\mathrm{O}$ elements are distributed within the entire sample, especially the bright spots in Fig. $2 \mathrm{~h}$ correspond to the Ag NPs in the high-angle annular dark field image (Fig. 2e). This indicates that deposition and doping of $\mathrm{Ag}$ can be simultaneously achieved in the prepared sample by such a sol-hydrothermal method. The chemical composition of the $\mathrm{Ag} / \mathrm{Ag}$-doped $\mathrm{TiO}_{2}$ nanostructure is also analyzed using energy dispersive spectroscopy, and the signals of $\mathrm{Ag}, \mathrm{Ti}$, and $\mathrm{O}$ are shown in Fig. 2j. The peaks of Ti and $\mathrm{O}$ are dominant in the EDS spectrum with a molar ratio higher than 1:2, indicating the presence of $\mathrm{V}_{\mathrm{O}}$ defects in the nanostructure.

To further shed light on the state of Ag in the samples, more samples were prepared by using of different concentrations of $\mathrm{AgNO}_{3}$ and their SEM images, UV-Vis absorption spectra, X-ray diffraction (XRD), and X-ray photoelectron spectroscopy (XPS) are illustrated in Supplementary Figs. 1-3. The strong absorption occurs between 400 and $800 \mathrm{~nm}$, the diffraction peaks emerged and shifted, and the change of chemical state and binding energy all reveal that deposition and doping of $\mathrm{Ag}$ are simultaneously exist in the Ag/Ag-doped $\mathrm{TiO}_{2}$ nanostructure ${ }^{25,31-33}$. The detailed analysis are contained in Supplementary Note 1.

NIR irradiation-induced SERS behaviors. The SERS characteristics of the prepared samples were measured at room temperature under irradiation of 785-nm wavelength laser, the set power $40 \mathrm{~mW}$ and the integration time $2 \mathrm{~s}$. The irradiation timedependent SERS spectra of the $4 \mathrm{MBA} / \mathrm{Ag} / \mathrm{Ag}$-doped $\mathrm{TiO}_{2}$ hybrid system prepared with $0.5 \mathrm{mM} \mathrm{AgNO}_{3}$ are shown in Fig. 3a. The Raman peaks at 88 and $148 \mathrm{~cm}^{-1}$ are in good agreement with the $\mathrm{Ag}-\mathrm{Ag}$ stretching vibration ${ }^{34,35}$ and the $\mathrm{O}-\mathrm{Ti}-\mathrm{O}$ symmetric stretching ${ }^{36}$, respectively. The SERS peak of $4 \mathrm{MBA}$ at $1078 \mathrm{~cm}^{-1}$ can be assigned to the in-plane ring breathing mode coupled with $v(\mathrm{C}-\mathrm{S})$, and the others dominant peaks at 1587 and $364 \mathrm{~cm}^{-1} \mathrm{can}$ be attributed to the aromatic ring $v(\mathrm{C}-\mathrm{C})$ vibration mode and the $\mathrm{Ag}-\mathrm{S}$ stretching vibration, respectively ${ }^{37,38}$. As clearly shown in Supplementary Fig. 4, other weak bands at 525 and $718 \mathrm{~cm}^{-1}$ are corresponding to ring out-of-plane bending, and the mode at 842 $\mathrm{cm}^{-1}$ is ascribed to $\mathrm{COO}^{-}$bending ${ }^{37}$. The temporal evolutions of the SERS peak intensities at $88,148,364,1078$, and $1587 \mathrm{~cm}^{-1}$ for the initial $100 \mathrm{~s}$ of irradiation are shown in Fig. $3 \mathrm{c}$ (phase I). Interestingly, the Raman signals of the Ag/Ag-doped $\mathrm{TiO}_{2}$ substrate exhibit an exponential decrease while, the main SERS signals of the 4MBA show an exponential increase, and all signals reach saturated level after $80 \mathrm{~s}$ of irradiation. And there are slight frequency shifts for the SERS spectra of 4MBA adsorbed on 

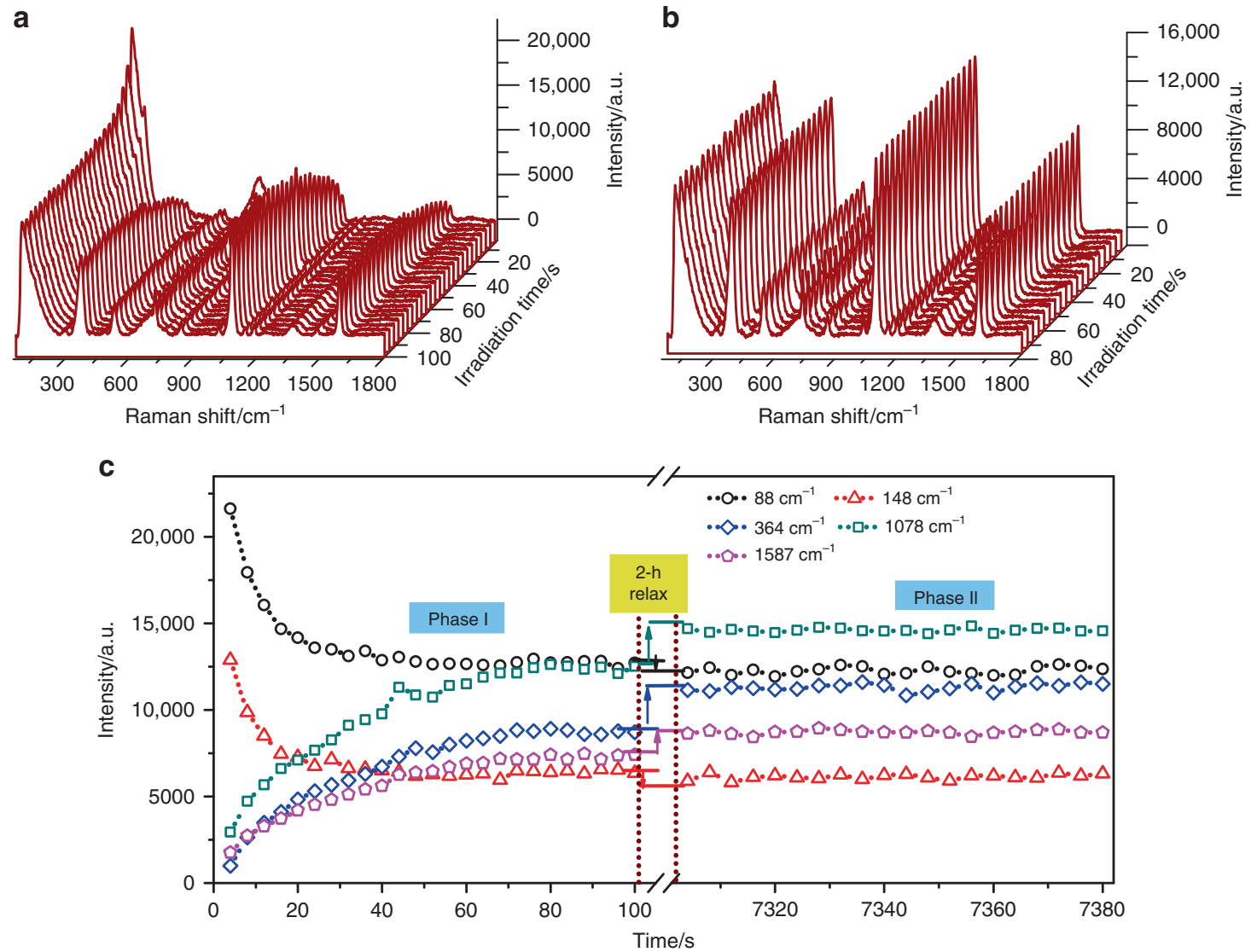

Fig. 3 Irreversible accumulated SERS behaviors. a NIR irradiation-induced SERS spectra of the $4 \mathrm{MBA} / \mathrm{Ag} / \mathrm{Ag}$-doped $\mathrm{TiO}_{2}$ hybrid system; b NIR irradiation-induced SERS spectra of the $4 \mathrm{MBA} / \mathrm{Ag} / \mathrm{Ag}$-doped $\mathrm{TiO}_{2}$ hybrid system after $2 \mathrm{~h}$ relaxation without irradiation; c Temporal evolutions of the Raman peak intensities at $88,148,364,1078$, and $1587 \mathrm{~cm}^{-1}$. Phase I: the SERS signals under continuous irradiation (100 s); phase II: after $2 \mathrm{~h}$ relaxation without irradiation and then under continuous irradiation ( $80 \mathrm{~s}$ ). Here, the temporal evolutions of other bands of $4 \mathrm{MBA}$, such as 525,718, and $842 \mathrm{~cm}^{-1}$, are not displayed due to their relative weak signal and same trends.

$\mathrm{Ag} / \mathrm{Ag}$-doped $\mathrm{TiO}_{2}$ substrate under NIR irradiation, as shown in Supplementary Fig. 5. In addition, the SERS spectra of the 4MBA/ Ag/Ag-doped $\mathrm{TiO}_{2}$ hybrid system were also measured by using 532 and $633 \mathrm{~nm}$ wavelength lasers, and observed similar phenomenon above (Supplementary Fig. 6). Furthermore, the sample was then kept at room temperature for $2 \mathrm{~h}$ without irradiation to ensure full relaxation, and measurement was resumed with the same setting and at the same position on the sample. The SERS spectra are shown in Fig. 3b, and the corresponding SERS intensities are plotted in Fig. $3 c$ (phase II). It can be seen the intensities of SERS peaks at 88 and $148 \mathrm{~cm}^{-1}$ drop slightly whereas the intensities of peaks at 364,1078 , and $1587 \mathrm{~cm}^{-1}$ show a step-like increase compared with the previous measurements shown in phase I, and subsequent intensities of the above SERS peaks show negligible change. To shed light on the cause of this phenomenon, the irradiation time-dependent SERS spectra of 4MBA/Ag/Ag-doped $\mathrm{TiO}_{2}$ hybrid systems prepared with different amounts of $\mathrm{AgNO}_{3}$ were measured and shown in Supplementary Fig. 7. Obviously, in the case of pure $\mathrm{Ag}$ or $\mathrm{TiO}_{2}$, the exponential changes of Raman peak intensities can be neglected, however, there are significant exponential trends for that of the $4 \mathrm{MBA} / \mathrm{Ag} / \mathrm{Ag}$-doped $\mathrm{TiO}_{2}$ hybrid system. And, as shown in Supplementary Fig. 8, the SERS spectra of 4MBA adsorbed on Ag/Ag-doped $\mathrm{TiO}_{2}$ substrate exhibits the peak frequency shift as function of the $\mathrm{AgNO}_{3}$ concentration. Therefore, the irradiation time-dependent SERS response of the 4MBA/Ag/Ag-doped $\mathrm{TiO}_{2}$ hybrid system is ascribed to the synergistic effect of $\mathrm{Ag}$ and $\mathrm{TiO}_{2}$.
To further characterize the SERS performances of as-prepared Ag/Ag-doped $\mathrm{TiO}_{2}$ substrates, as described in Supplementary Note 2, the SERS spectra of $4 \mathrm{MBA} / \mathrm{Ag} / \mathrm{Ag}$-doped $\mathrm{TiO}_{2}$ hybrid systems before and after NIR irradiation and the normal Raman spectrum of neat 4MBA are shown in Supplementary Fig. 9, and the enhancement factors (EFs) corresponding to each $\mathrm{Ag} / \mathrm{Ag}$ doped $\mathrm{TiO}_{2}$ substrate are calculated in detail and listed in Supplementary Table 1. Of the particular note, the Ag/Ag-doped $\mathrm{TiO}_{2}$ substrate prepared with $0.5 \mathrm{mM} \mathrm{AgNO}$ display well SERS activities, especially after NIR irradiation, the EF increased from $2.88 \times 10^{5}$ to $1.68 \times 10^{6}$, nearly six-fold, which is better than that of bare-Ag NPs. And from Supplementary Table 2, compared the our work with the reported literatures, it clearly shows that the 4MBA/Ag/Ag-doped $\mathrm{TiO}_{2}$ hybrid system achieves the higher enhancement after NIR irradiation. Therefore, the prepared 4MBA/Ag/Ag-doped $\mathrm{TiO}_{2}$ hybrid system will present their advantages in trace detection applications.

In addition, we also carried out another experiment to get the temporal evolution of the SERS peak intensity of the 4MBA/Ag/Agdoped $\mathrm{TiO}_{2}$ hybrid system by blocking/unblocking of laser irradiation, which is shown in Supplementary Fig. 10. As a typical temporal evolutions course, we find that the peak intensity at $1078 \mathrm{~cm}^{-1}$ remains in a stable value when the laser was switched off, and then resumes increasion after the laser was switched on. This clearly demonstrates that the temporal evolution of the SERS peak intensity is irreversible and only depends on the cumulative irradiation time not on the total time begining from the initial state. 

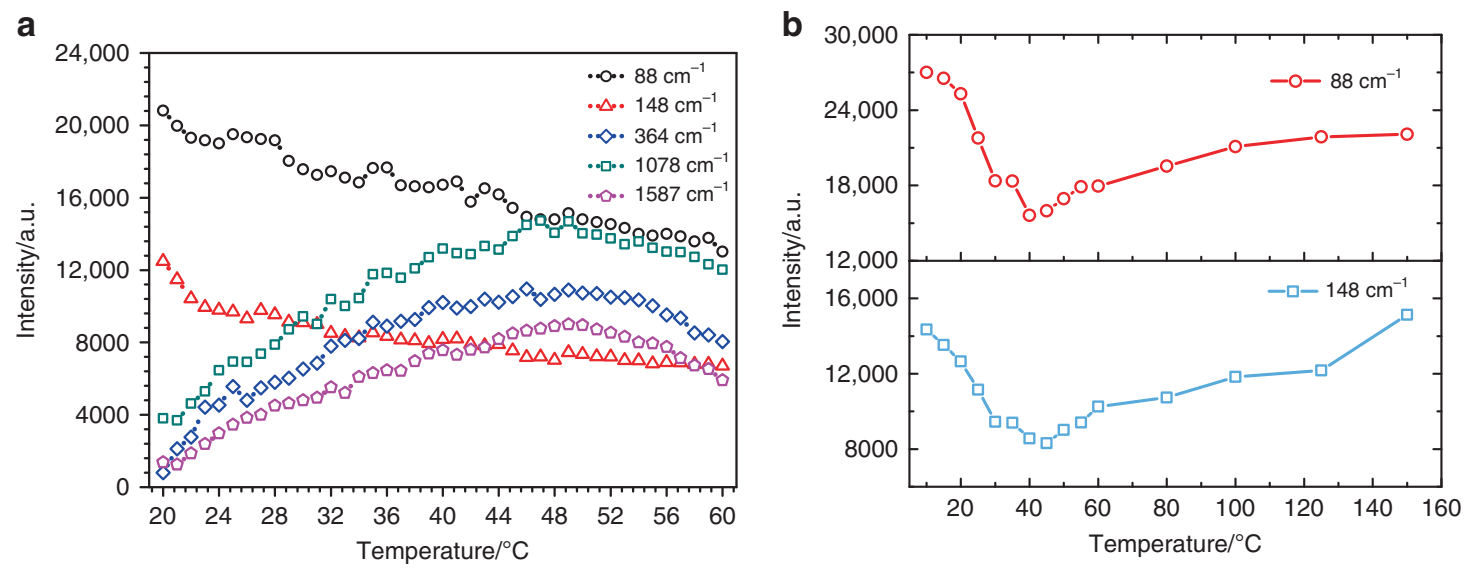

Fig. 4 Temperature effect. a Temperature-dependent SERS peak intensities of the $4 \mathrm{MBA} / \mathrm{Ag} / \mathrm{Ag}$-doped $\mathrm{TiO}_{2}$ hybrid system. $\mathbf{b} \mathrm{Temperature-dependent} \mathrm{of}$ Raman peak intensities of the $\mathrm{Ag} / \mathrm{Ag}$-doped $\mathrm{TiO}_{2}$ substrate.

Temperature effect. As mentioned by earlier researchers, NIR irradiation tends to excite the defects and heat up the substrate, the change of defect charging state and the increase of substrate temperature give rise to Raman signal variation ${ }^{39-42}$. To gain an insight into the above experimental observations, we investigated the temperature effect as well as the defect dynamics on the temporal evolution of the SERS peak intensity. The temperaturedependent SERS spectra of the $4 \mathrm{MBA} / \mathrm{Ag} / \mathrm{Ag}$-doped $\mathrm{TiO}_{2}$ hybrid system were recorded in the range of 20 to $60^{\circ} \mathrm{C}$ with an interval of $1{ }^{\circ} \mathrm{C}$ and shown in Fig. 4a. The SERS peak intensities of 4MBA increase with increasing temperature from 20 to $50^{\circ} \mathrm{C}$, which reproducing the temperature effect, that is, higher temperature inducing the increase of free electron density and promoting the CT between the $4 \mathrm{MBA}$ molecules and substrate ${ }^{41,43,44}$. However, when the temperature exceeds $50^{\circ} \mathrm{C}$, the SERS peak intensities of 4MBA decrease. This can be attributed to the structure of the $4 \mathrm{MBA} / \mathrm{Ag} / \mathrm{Ag}$-doped $\mathrm{TiO}_{2}$ hybrid system has been destroyed at high temperatures ${ }^{41,42}$. In addition, it is also found that the Raman peak intensities of $\mathrm{Ag}$ at $88 \mathrm{~cm}^{-1}$ and $\mathrm{TiO}_{2}$ at $148 \mathrm{~cm}^{-1}$ decrease with increasing temperature, which is discrepant from the usual observation ${ }^{36,45}$. To clarify the above temperature effects, one set of control experiments was conducted and the results are shown in Supplementary Fig. 11. According to the analyses in Supplementary Note 3, it is deduced that the impact of temperature on the irreversible enhancement of the SERS signal of $4 \mathrm{MBA}$ can be excluded because there is no change of the 4MBA molecule characteristics during go through an annealing treatment. However, the temperature induces a permanent change to the microstructure of the $4 \mathrm{MBA} / \mathrm{Ag} / \mathrm{Ag}$-doped $\mathrm{TiO}_{2}$ hybrid system, resulting in the discrepancy of the Raman behavior encountered a higher temperature stressing.

To further investigate the irradiation time-dependent SERS characteristics of the pure substrate, the SERS spectra of the Ag/ Ag-doped $\mathrm{TiO}_{2}$ substrate were measured and shown in Supplementary Fig. 12. The SERS peak intensities of $\mathrm{Ag}$ $\left(88 \mathrm{~cm}^{-1}\right)$ and $\mathrm{TiO}_{2}\left(148 \mathrm{~cm}^{-1}\right)$ decrease with increasing irradiation time, which are same as the spectra in Figs. 3a and 4a. Considering irradiation as a direct factor, XPS measurement was performed to investigate the structure change of the $\mathrm{Ag} / \mathrm{Ag}$ doped $\mathrm{TiO}_{2}$ substrate before and after irradiation by the $785-\mathrm{nm}$ laser. As shown in Supplementary Fig. 13, the XPS spectra support the fact that the irradiation reduces the density of $\mathrm{V}_{\mathrm{O}}$ defects in the substrate and consequently improve the crystalline structure $^{46}$. At same time, the laser irradiation heats up the substrate and helps the defect self-repairing ${ }^{47}$, thus, the Raman spectra of the $\mathrm{Ag} / \mathrm{Ag}$-doped $\mathrm{TiO}_{2}$ substrate (Supplementary
Fig. 14) were measured under different annealing temperatures for converting the role of irradiation time into the temperature effect. As shown in Fig. 4b, the Raman peak intensities located at 88 and $148 \mathrm{~cm}^{-1}$ exhibit parabola-like characteristics. The peak intensities first decrease with increasing temperature from 10 to $45^{\circ} \mathrm{C}$, which is consistent with the irradiation time-dependent peak intensities observed in Supplementary Fig. 12b. With further increase of temperature, the peak intensities steadily increase, similar to previous published results $36,45,48$.

In fact, it is recognized that the mobility of the atom will increase under high temperature and help repairing the defects in the material. In our case, the irradiation-generated photothermal effect will also reduce the density of $\mathrm{V}_{\mathrm{O}}$ defects in the $\mathrm{Ag} / \mathrm{Ag}$ doped $\mathrm{TiO}_{2}$ substrate and improve the crystallinity. The better crystallinity of the $\mathrm{Ag} / \mathrm{Ag}$-doped $\mathrm{TiO}_{2}$ substrate, the more $\mathrm{O}-\mathrm{Ti}-\mathrm{O}$ bonds, resulting in higher Raman intensity. On the other hand, the Raman intensity not only depends on the crystallinity but also strongly related to the electron polarizability of the material ${ }^{49,50}$. A superior crystallinity material will give rise to higher Raman intensity, but the higher compactness of material will weaken the electron polarizability. In these two competitive processes, the electron polarizability degradation is the dominated factor and causes the Raman intensity to decrease in the range of $10-45^{\circ} \mathrm{C}$ (Fig. $4 \mathrm{~b}$ ), which are corresponded to the irradiation time-dependent SERS characteristics of the $\mathrm{Ag} / \mathrm{Ag}$ doped $\mathrm{TiO}_{2}$ substrate (Supplementary Fig. 12). This is also supported by the first principles calculation of Raman intensity for the anatase $\mathrm{TiO}_{2}$ in Supplementary Note 4 . And the calculated polarizability tensor invariants of the anatase $\mathrm{TiO}_{2}$ with different concentrations of $\mathrm{V}_{\mathrm{O}}$ defects are listed in Supplementary Table 3. As shown in Fig. 5a, a polynomial function is used to fit these data, and the relationship between the polarizability of the anatase $\mathrm{TiO}_{2}$ and the concentration of $\mathrm{V}_{\mathrm{O}}$ defects is obtained. It is obviously seen that the polarizability of the anatase $\mathrm{TiO}_{2}$ increases with the growth concentration of $\mathrm{V}_{\mathrm{O}}$ defects, except for very low and high concentrations of $\mathrm{V}_{\mathrm{O}}$ defects. And then according to the Supplementary Equation (2), the Raman intensity as a function of the concentration of $V_{O}$ defects is plotted in Fig. 5b. It can be found that the Raman intensity first decreases and then increases with decreasing the concentration of $\mathrm{V}_{\mathrm{O}}$ defects. The calculation displays a similar trend consisted with the experiment data and is well explanation for experimental results (Fig. 4b). Furthermore, to study the temperature effect on the Raman intensity of $\mathrm{Ag}-\mathrm{Ag}$ interaction, the thermogravimetric and differential scanning calorimetry (TGA/DSC) analysis on the Ag/Ag-doped $\mathrm{TiO}_{2}$ substrate was implemented under the $\mathrm{N}_{2}$ 
a

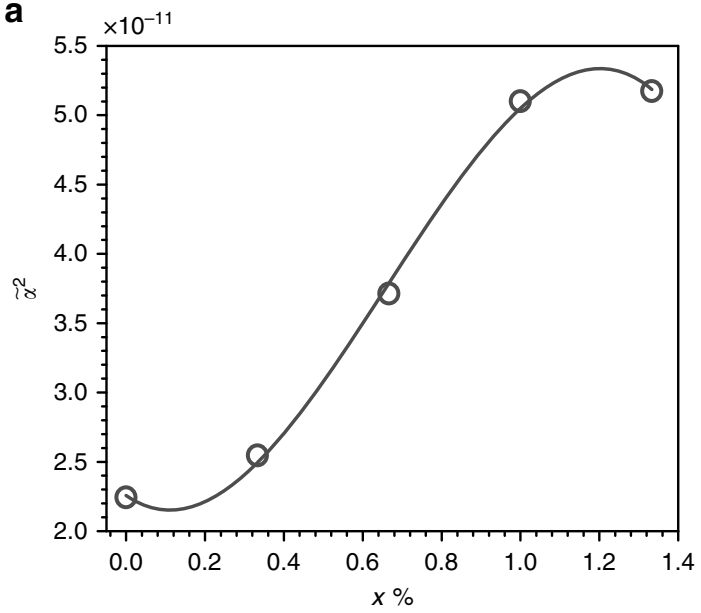

b

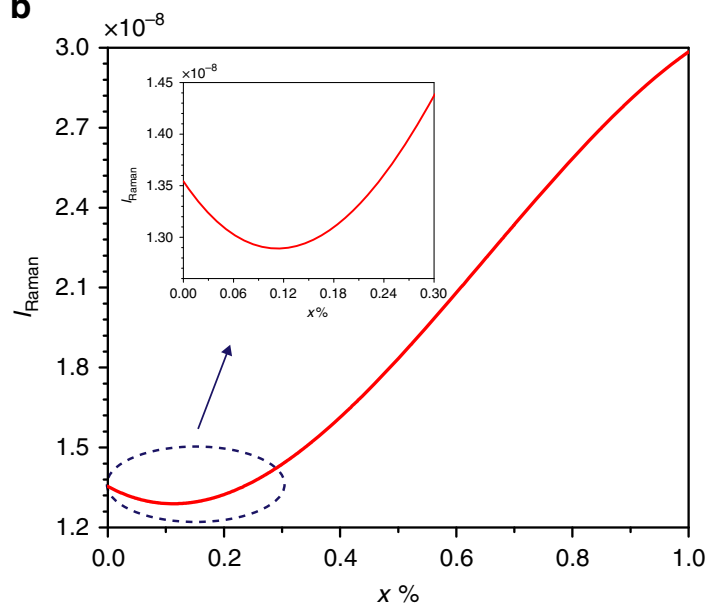

Fig. 5 First principles calculation for $\mathbf{T i O}_{\mathbf{2}}$. a $\tilde{\alpha}^{2}$ vs. $x$, and the fitted polynomial curve (red line); $\mathbf{b} I_{\text {Raman }}$ vs. $x$ for the anatase $\mathrm{TiO}_{2}$.

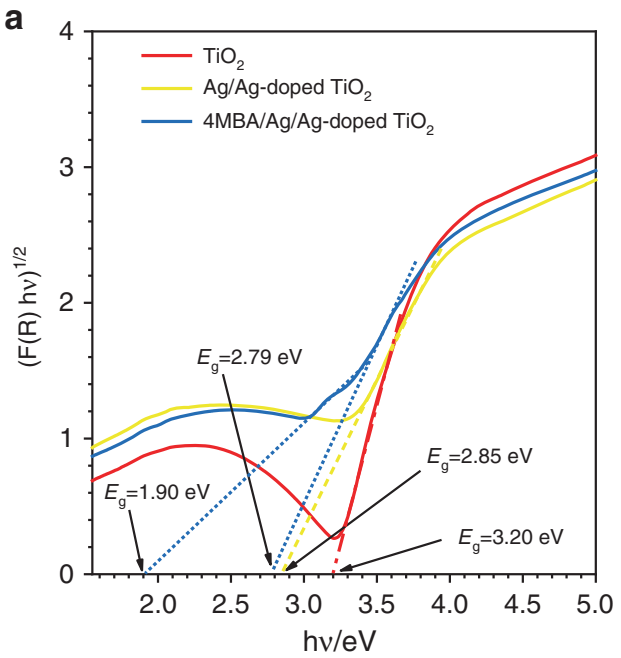

b

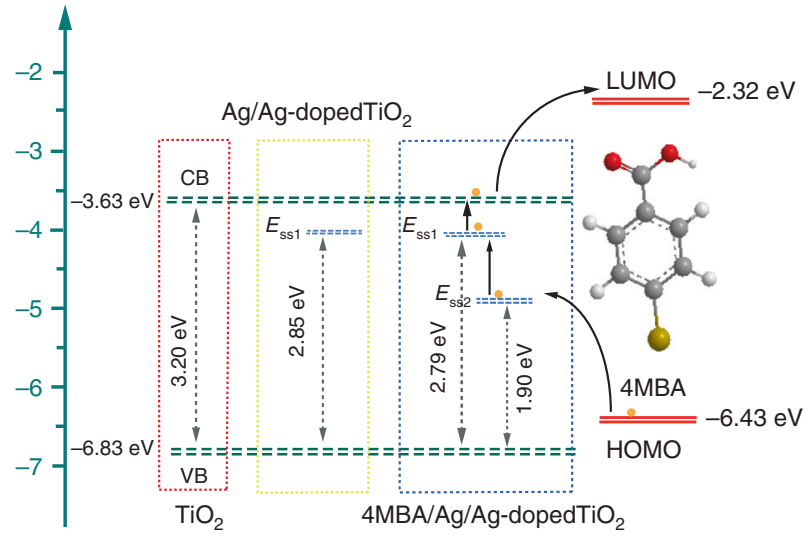

Fig. 6 Diagram of energy levels. a Curves of $(\mathrm{F}(\mathrm{R}) h \nu)^{1 / 2}$ vs. $h \nu$ for $\mathrm{TiO}_{2}, \mathrm{Ag} / \mathrm{Ag}$-doped $\mathrm{TiO}_{2}$ substrate and $4 \mathrm{MBA} / \mathrm{Ag} / \mathrm{Ag}$-doped TiO 2 hybrid system, respectively. $\mathbf{b}$ Schematic diagram illustrating the photo-induced $\mathrm{CT}$ between the $\mathrm{Ag} / \mathrm{Ag}$-doped $\mathrm{TiO}_{2}$ substrate and $4 \mathrm{MBA}$ molecule under the excitation of 785-nm laser.

ambient and shown in Supplementary Fig. 15. The temperaturedependent SERS characteristics of $\mathrm{Ag}-\mathrm{Ag}$ interaction are attributed to the breaking of the weak interactions between $\mathrm{Ag}$ ions and the producing of elemental Ag (Supplementary Fig. 16). The detailed analysis can be found in Supplementary Note 5.

Photo-induced CT. The UV-Vis diffuse reflectance spectra (DRS) of pure $\mathrm{TiO}_{2}, \mathrm{Ag} / \mathrm{Ag}$-doped $\mathrm{TiO}_{2}$ substrate, and $4 \mathrm{MBA} / \mathrm{Ag} / \mathrm{Ag}$ doped $\mathrm{TiO}_{2}$ hybrid system were obtained from the reflectance spectra using the Kubelka-Munk equation (See Supplementary Fig. 17 $)^{51,52}$. And Fig. 6 a shows the determination of the indirect band gaps of $\mathrm{TiO}_{2}, \mathrm{Ag} / \mathrm{Ag}$-doped $\mathrm{TiO}_{2}$ substrate and $4 \mathrm{MBA} / \mathrm{Ag} / \mathrm{Ag}$ doped $\mathrm{TiO}_{2}$ hybrid system by plotting of $[\mathrm{F}(\mathrm{R}) h v]^{1 / 2} \sim h v$ curves ${ }^{53}$. Then, the band gap of pure $\mathrm{TiO}_{2}$ and the Ag/Ag-doped $\mathrm{TiO}_{2}$ substrate are obtained to be 3.20 and $2.85 \mathrm{eV}$, respectively. The lowering of band gap of the $\mathrm{Ag} / \mathrm{Ag}$-doped $\mathrm{TiO}_{2}$ substrate is due to the presence of $\mathrm{V}_{\mathrm{O}}$ defects. Further, the band gap of the 4MBA/Ag/ Ag-doped $\mathrm{TiO}_{2}$ hybrid system is $1.9 \mathrm{eV}$, which is attributed to the influence of molecules adsorbed on the $\mathrm{Ag} / \mathrm{Ag}$-doped $\mathrm{TiO}_{2}$ substrate. And the lower levels are denoted as surface-state level $\mathrm{E}_{\mathrm{ss} 1}$ and $\mathrm{E}_{\mathrm{ss} 2}$, respectively. According to the literatures ${ }^{54,55}$, the conduction band (CB) and valence band (VB) levels of $\mathrm{TiO}_{2}$ are -3.63 and $-6.83 \mathrm{eV}$, and the highest occupied molecular orbital (HOMO) and the lowest unoccupied molecular orbital (LUMO) levels of $4 \mathrm{MBA}$ are -6.43 and $-2.32 \mathrm{eV}$, respectively. As illustrated in Fig. 6b, the direct transition of electrons from the $\mathrm{VB}$ of $\mathrm{TiO}_{2}$ to $\mathrm{E}_{\mathrm{ss} 2}$ require an excitation energy of $1.90 \mathrm{eV}$, while the excitation energy provided by the $785-\mathrm{nm}$ laser is only $1.58 \mathrm{eV}$, which means that their possible CT process is ruled out. However, the laser energy is sufficiently high and larger than the excitation energy $(1.50 \mathrm{eV})$ required for the direct transition of electrons from the HOMO of $4 \mathrm{MBA}$ to $\mathrm{E}_{\mathrm{ss} 2}$, which enables their possible CT process. With the help of abundant surface-state levels, the electrons will be promoted from the $\mathrm{HOMO}$ of $4 \mathrm{MBA}$ to the $\mathrm{E}_{\mathrm{ss} 2}$ and $\mathrm{E}_{\mathrm{ss} 1}$ of the $4 \mathrm{MBA} / \mathrm{Ag} / \mathrm{Ag}$ doped $\mathrm{TiO}_{2}$ hybrid system upon illuminating of 785-nm laser, then transferred to $\mathrm{CB}$ of $\mathrm{TiO}_{2}$, and finally transferred to LUMO of 4MBA. This photo-induced CT will lead to magnification of Raman scattering cross-section, that is, enhance the Raman signal of 4MBA.

To verify the SERS enhancement derived from the above photo-induced CT, the SERS spectra of 4MBA adsorbed on Ag NPs, $\mathrm{TiO}_{2}$ and the Ag/Ag-doped $\mathrm{TiO}_{2}$ substrate were measured and shown in Supplementary Fig. 18. Obviously, their SERS spectra display significantly differences, particularly the relative intensity of the Raman mode. As well known, the Raman modes 
can be divided into two categories: totally symmetric vibration mode $\left(\mathrm{a}_{1}\right)$ with an intensity not responsive to CT; the other is non-totally symmetric vibration mode $b_{2}$. The CT contribution is the main reason for the selectivity enhancement of $b_{2}$ mode $22,25,56$. To eliminate the impact of the electromagnetic mechanism, the peak at $1078 \mathrm{~cm}^{-1}$ belonging to the $a_{1}$ mode was selected as reference, and the peak intensity ratios of the $b_{2}$ to $a_{1}$ mode $\left(R=\mathrm{I}_{\mathrm{b} 2} / \mathrm{I}_{\mathrm{a} 1}\right)$ are listed in Supplementary Table 4 . It can be found that the $R$ values of $\mathrm{Ag} / \mathrm{Ag}$-doped $\mathrm{TiO}_{2}$ substrate are larger than that of Ag NPs, which reveal that the signal enhancement of $\mathrm{b}_{2}$ modes are attributed to CT mechanism.

Reorientation of 4MBA molecules. Although the CT effect indeed resulted in the Raman signal enhancement of $4 \mathrm{MBA}$ adsorbed on the $\mathrm{Ag} / \mathrm{Ag}$-doped $\mathrm{TiO}_{2}$ substrate, the irreversible accumulated SERS enhancement of $4 \mathrm{MBA}$ cannot be completely explained by CT, and further analysis is required. It is well known that after the CT process, a sheet layer of positive charge will be formed on the surface of the $\mathrm{Ag} / \mathrm{Ag}$-doped $\mathrm{TiO}_{2}$ substrate, while the adsorbed molecule is negatively charged, thus, electrostatic attraction can be expected to exist between the substrate and the molecule. Here, an overdamping movement model is developed to fully describe the reorientation of the molecule adsorbed on the substrate for explaining the irreversible and exponential accumulated enhancement of the Raman signal. As shown in the inset of Fig. 7a, the 4MBA molecule is anchored onto the surface of the Ag/Ag-doped $\mathrm{TiO}_{2}$ substrate through the Ag-S bond, and the electrostatic attraction caused by CT will force the 4MBA molecule to move towards the substrate, but the stretched Ag-S bond and other neighboring molecule will obstruct this movement, making $4 \mathrm{MBA}$ molecule difficult to lie flat on the surface of substrate. As a result, based on the physical model shown in Fig. 7a, an analytical expression of the SERS peak intensity as the function of the irradiation time $t$ can be derived:

$$
I_{\mathrm{SERS}}(t)=\alpha \exp \left\{-4 \kappa r \sin \left[\theta_{\infty}+\frac{1}{2}\left(\theta_{0}-\theta_{\infty}\right)(\beta t+2) \exp \left(-\frac{\beta}{2} t\right)\right]\right\},
$$

where $\alpha, \kappa, \beta$ are constants, $r$ is the position of the functional group that corresponds to Raman peak, $\theta_{0}$ and $\theta_{\infty}$ are the initial angle and last orientation angle of molecule, respectively.

Next, as the calculated result of the suitable parameters, the exponential signal increase in Fig. 3c (Phase I) can be exactly reproduced by Eq. (1) and is shown in Fig. 7b. As for the step-like increase of the SERS signal observed in Fig. 3c (Phase II), it can be explained as follows: after a long relaxation process (without laser irradiation), the molecules will stay in a stable state; then, once the laser resumed, the molecule obtains a sudden initial acceleration under the action of electrostatic force created by the photo-induced CT, this will trigger the molecule to move towards the substrate again and result in an increase of SERS signal; at this moment, however, the damping force will also balance the electrostatic force to stop the molecule movement. As a result, a sudden jump of the SERS signal can be expected, and then the signal will remain unchanged even with increasing irradiation time.

In fact, the Raman frequency shift of $4 \mathrm{MBA}$ molecule adsorbed on $\mathrm{Ag} / \mathrm{Ag}$-doped $\mathrm{TiO}_{2}$ substrate under NIR irradiation (Supplementary Fig. 5) has also presented the molecule reorientation on the surface of substrate $e^{57,58}$. To further verify the reorientation behavior of adsorbed molecule, the irradiation time-dependent SERS spectra of three other molecules, 4-nitrothiophenol (4NTP), crystal violet $(\mathrm{CV})$ and rhodamine $6 \mathrm{G}(\mathrm{R} 6 \mathrm{G})$, were measured and shown in Supplementary Fig. 19. Similar to 4MBA, the SERS spectra of 4NTP also exhibits an irreversible and exponentially accumulated increase with increasing of irradiation time, because the 4NTP molecule is adsorbed to the surface of the Ag/Ag-doped $\mathrm{TiO}_{2}$ substrate by $\mathrm{Ag}-\mathrm{S}$ bonds and reoriented through a CT process. However, the SERS spectra of CV and R6G adsorbed on Ag/Ag-doped $\mathrm{TiO}_{2}$ substrate have no significant change with increasing of irradiation time. This is because the $\mathrm{CV}$ and $\mathrm{R} 6 \mathrm{G}$ molecules are attracted on the surface of $\mathrm{Ag} / \mathrm{Ag}$-doped $\mathrm{TiO}_{2}$ substrate by electrostatic interaction, no chemical bond, which suggests no molecular reorientation. In addition, as shown in Supplementary Fig. 20a, two new SERS peaks of 4MBA at 842 and $1364 \mathrm{~cm}^{-1}$ are, respectively, ascribed to the $v_{s}(\mathrm{COO}-)$ and $\delta$ $(\mathrm{COO}-)$ vibrations ${ }^{37}$, and rise with increasing of irradiation time

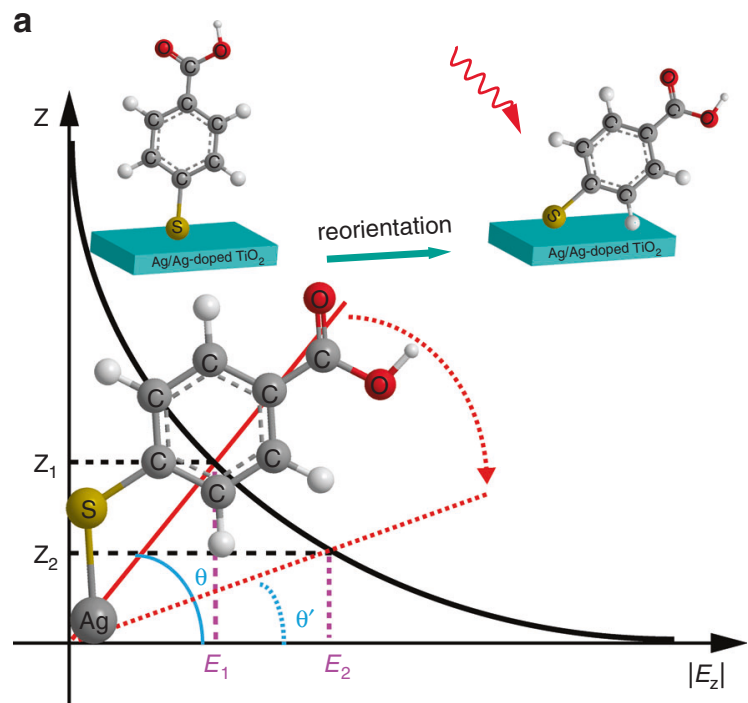

b

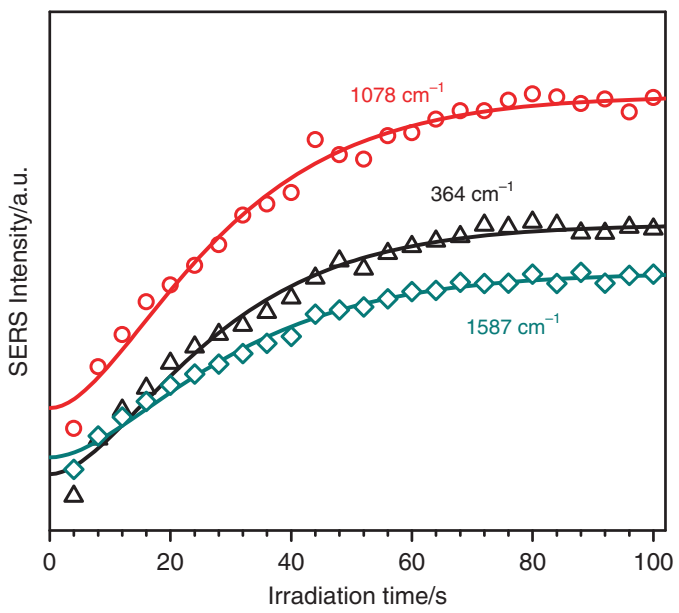

Fig. 7 Reorientation of 4MBA molecules. a Physical model of $4 \mathrm{MBA}$ molecule movement in an exponentially decaying electromagnetic field with increasing of the distance $Z$ perpendicular to the surface of substrate. The inset is the reorientation schematic of $4 \mathrm{MBA}$ molecule on the surface of the $\mathrm{Ag} /$ Ag-doped $\mathrm{TiO}_{2}$ substrate under laser irradiation. $\mathbf{b}$ Irradiation time-dependent SERS peak intensities of $4 M B A$ at 364,1078 , and $1587 \mathrm{~cm}^{-1}$, experimental data (symbols) and theoretical results (solid lines). 
due to the molecular movement toward to surface of substrate. Similarly, the new Raman mode of 4NTP appeared at $1304 \mathrm{~cm}^{-1}$ (Supplementary Fig. 20b), which could come from the new chemical bonding between $\mathrm{Ag} / \mathrm{Ag}$-doped $\mathrm{TiO}_{2}$ substrate and $4 \mathrm{NTP}$ through the nitrogen atom ${ }^{59}$. Consequently, it confirms again that our proposed molecular reorientation model is reasonable.

\section{Discussion}

In summary, by studying the SERS characteristic of molecule/Ag/ Ag-doped $\mathrm{TiO}_{2}$ hybrid system, the NIR light-induced irreversible accumulated SERS behavior has been observed and the underlying mechanism explained. On the one hand, Raman signal of the Ag/Ag-doped $\mathrm{TiO}_{2}$ substrate exhibits an irreversible and exponential decrease with increasing of irradiation time, which resulted from the reduction of $\mathrm{V}_{\mathrm{O}}$ defects caused by temperature effect under irradiation of 785-nm laser, in other words, higher temperature improving the crystallinity and reducing the polarizability of the substrate. On the other hand, the SERS signal of $4 \mathrm{MBA}$ molecule linked with the substrate shows an irreversible and exponential accumulated increase with increasing of irradiation time, which can be ascribed to the reorientation of $4 \mathrm{MBA}$ molecule bending towards the surface of substrate through an overdamping process, once triggering the CT between 4MBA molecule and substrate.

The results enable better understanding of the SERS mechanism in the molecule/metal-semiconductor hybrid system and open up a new approach for fabricating other functional SERS substrates of metal-semiconductor, such as $\mathrm{Au}-\mathrm{TiO}_{2}, \mathrm{Ag}-\mathrm{V}_{2} \mathrm{O}_{5}$, and $\mathrm{Ag}-\mathrm{MoO}_{2}$. Furthermore, the concept of irreversible accumulated SERS characteristics of molecule/metal-semiconductor hybrid system maybe also provides an alternative technical strategy to construct effective SERS platform for the applications of ultrasensitive bio-detection, real-time monitoring of catalytic reaction, and fingerprint identification of molecular self-assembly.

\section{Methods}

Chemical and materials. Titanium (Ti) foil, sodium hydroxide $(\mathrm{NaOH})$, and trisodium citrate $\left(\mathrm{Na}_{3} \mathrm{C}_{6} \mathrm{H}_{5} \mathrm{O}_{7} \mathrm{~S}_{2} \mathrm{H}_{2} \mathrm{O}\right)$ were purchased from Aladdin. Silver nitrate $\left(\mathrm{AgNO}_{3}\right)$ was purchased from Sigma-Aldrich. 4MBA was obtained from J\&K Chemical. Hydrogen fluoride (HF) was purchased from Wuxi Chenyang Chemical Co., Ltd. All chemicals were in analytical grade and used as-received. Milli-Q water (specific resistance $>18.2 \mathrm{M} \Omega \mathrm{cm}$ ) was used throughout the whole experiment. Glassware was cleaned by aqua regia and rinsed with deionized water several times prior to experiments.

Synthesis of $\mathbf{A g} / \mathbf{A g}$-doped $\mathrm{TiO}_{\mathbf{2}}$ substrate. Eight pieces of Ti foils $(10 \times 15$ $\mathrm{mm}^{2}$ ) were ultrasonically cleaned with acetone for $20 \mathrm{~min}$ and with deionized water for $10 \mathrm{~min}$. After the ultrasonic treatment, the Ti foils were immersed in HF $(40 \%)$ and deionized water with a volume ratio of 30:1 for 5-10 s. Thereafter, the pre-treated Ti foils were added into $15 \mathrm{~mL}$ of mixture solution that contained $5 \mathrm{M}$ of $\mathrm{NaOH}, 0.25 \mathrm{mM}$ of trisodium citrate and different concentrations of $\mathrm{AgNO}_{3}(0$, $0.1,0.2,0.3,0.4,0.5,0.6$, and $0.7 \mathrm{mM}$ ) in the Teflon pot, respectively. The mixed reactants were transferred to $25 \mathrm{~mL}$ of autoclaves, sealed and maintained at $150{ }^{\circ} \mathrm{C}$ for $16 \mathrm{~h}$. After that, the autoclaves were naturally cooled down to room temperature, and the products were rinsed in the deionized water. While the surfaces of $\mathrm{Ti}$ foil were adsorbed by ivory thin films which were the $\mathrm{Na}_{2} \mathrm{TiO}_{3}$. To obtain anatase $\mathrm{TiO}_{2}$, the products were subjected to the hydrolysis reaction at $150{ }^{\circ} \mathrm{C}$ for $5 \mathrm{~h}$. Again, after cleaned by deionized water, the appearance of off-white surfaces of the $\mathrm{Ti}$ foils indicated the Ag/Ag-doped $\mathrm{TiO}_{2}$ substrate with different ratio of $\mathrm{Ag}$ have been successfully synthesized.

Measurement and equipment. SEM images were obtained by a field-emission SEM (SU-70, Hitachi, Japan) at an accelerating voltage of $5 \mathrm{kV}$. TEM images, SAED patterns, and STEM EDS mapping were obtained using a TEM (F200x, Talos, USA) operated at an accelerating voltage of $200 \mathrm{kV}$. The UV-Vis DRS were monitored with a spectrometer (Cary 5000, Agilent) and UV-vis absorption spectra were recorded with Pgeneral TU-1901. The XPS experiments were performed using monochromatic Al X-ray sources (AXIS ULTRA DLD, Kratos, UK). The XRD pattern was measured by using D8 Advance diffractometer equipped with a LynxEye XE detector (Bruker-AXS, Karlsruhe, Germany). SERS signals were measured by using a Raman spectrometer (BWS415, B\&W Tek Inc.) which is equipped with a semiconductor laser $(785 \mathrm{~nm}, 499.95 \mathrm{~mW})$, a dispersed grating of 1200 lines $\mathrm{mm}^{-1}$ and a charge-coupled device $(2048 \times 2048$ pixels $)$ detector. All the analyses were performed at room temperature. And another Raman spectrometer (Renishaw inVia) is used to measure the Raman spectra at light wavelength of 633 and $532 \mathrm{~nm}$.

Model and mathematics. As shown in main text, 4MBA molecule is adsorbed on the surface of $\mathrm{Ag} / \mathrm{Ag}$-doped $\mathrm{TiO}_{2}$ substrate by $\mathrm{Ag}-\mathrm{S}$ bond, and the benzene ring and $\mathrm{COOH}$ group can rotate round the bond. Normally, $4 \mathrm{MBA}$ molecules should orient to the surface at an approximate angle of $57^{\circ}$ for a close-packed selfassembled monolayers ${ }^{60}$. During light irradiation, the reorientation of $4 \mathrm{MBA}$ molecules are subject to the actions of electric-field force, damping fore, and restoring force. The electric-field force originates in the action of the evanescent field of surface plasmon on the negative charges of molecules due to CT, the damping fore results from the impede motion of other molecules, and the restoring force issues from the deformation resistance of $\mathrm{Ag}-\mathrm{S}$ bond. Considering the symmetric axial motion and ignoring the precession motion, the molecular orientation can be presented by Euler angle $\theta$. For simplicity, 4MBA molecule is analogy as a rigid dielectric slender rod, then the motion of the molecular bonded on the Ag/Ag-doped $\mathrm{TiO}_{2}$ substrate can be regard as the rotation of rod with fixed end. According to the rigid body dynamics, the motion of rod can be expressed as following equation:

$$
J \frac{d^{2} \theta(t)}{d t^{2}}=-A \frac{d \theta(t)}{d t}+B\left[\theta_{0}-\theta(t)\right]+C
$$

and

$$
A=\frac{1}{3} \mu L^{2}, B=\frac{1}{3} \eta L, C=-\frac{q_{o}}{L} \int \frac{L}{o} r E_{\mathrm{loc}}(r) d r,
$$

where $J$ is the moment inertia of rod, $\theta_{0}$ is the initial orientation position, $\mu$ is damping coefficient, $\eta$ is restoration coefficient, $L$ is length of rod, $q_{0}$ is the electric quantity of charges and assumed evenly distribute on the rod, $r$ is radial coordinate along rod, $E_{\mathrm{loc}}(r)=E_{0} \exp [-\kappa r \sin \theta(t)]$ is the electric-field intensity of surface plasmons $s^{61}, E_{0}$ is the electric-field intensity located at the surface of substrate, $k$ is decay length in $Z$ direction perpendicular to the substrate surface, $d_{r}$ is a small differential length in rod. Therefore, for the overdamping case and adopting first approximation condition, the rotation of rod follows the motion equation:

$$
\theta(t)=\theta_{\infty}+\frac{1}{2} \exp \left(-\frac{\beta}{2} t\right)(\beta t+2)\left(\theta_{0}-\theta_{\infty}\right),
$$

where $\theta_{\infty}$ is the final oriented position of $\operatorname{rod}, \beta=\mu / m, m$ is the molecular mass. Equation (3) gives the relation between the orientation angle $\theta$ and time $t$, which presents the orientation movement of molecular.

On the other hand, for the molecules adsorbed on plasmon NPs, the SERS enhancement is usually explained as the electromagnetic effect originating from the local enhanced electric field at the incident frequency $\omega_{0}$ and the radiation enhancement at the Raman scattering frequency $\omega_{\mathrm{R}}^{9,62,63}$. Thus, the SERS EF $G$ is introduced for quantifying the influence of the electromagnetic effect on the Raman scattering and can be expressed as ${ }^{9,61,64,65}$ :

$$
G=G_{1}\left(\omega_{0}\right) G_{2}\left(\omega_{R}\right)=\frac{\left|E_{l o c}\left(\omega_{0}\right)\right|^{2}\left|E_{l o c}\left(\omega_{R}\right)\right|^{2}}{\left|E_{\text {inc }}\left(\omega_{0}\right)\right|^{2}\left|E_{\text {inc }}\left(\omega_{R}\right)\right|^{2}} .
$$

In normal cases, the Raman shift is small and $\omega_{0} \approx \omega_{R}$. Then, from Eq. (4), $G$ is approximately written into:

$$
G \approx \frac{\left|E_{l o c}\left(\omega_{0}\right)\right|^{4}}{\left|E_{\text {inc }}\left(\omega_{0}\right)\right|^{4}},
$$

where $E_{l o c}\left(\omega_{0}\right)$ and $E_{\text {inc }}\left(\omega_{0}\right)$ are the local electric field around the plasmons NPs and the incident electric field at the incident frequency $\omega_{0}$, respectively.

In our experiments, according to Eq. (3), accompanying with the changes of molecular orientation, the evanescent field of surface plasmon acted on the molecules is changed as following equation:

$$
E_{l o c}(r)=E_{0} \exp \left\{-\kappa \mathrm{rsin}\left[\theta_{\infty}+\frac{1}{2} \exp \left(-\frac{\beta}{2} t\right)(\beta t+2)\left(\theta_{0}-\theta_{\infty}\right)\right]\right\} .
$$

Here, only considering the influence of the electromagnetic effect, then the SERS EF $G$ is equivalent to the enhancement efficiency of the plasmon NPs on the Raman scattering of molecules, that is, $G=I_{\text {SERS }} / I_{\text {Raman }}$, where $I_{\text {SERS }}$ and $I_{\text {Raman }}$ are the SERS intensity and Raman intensity of adsorbed molecules in the presence and absence of plasmon NPs, respectively. And combining of Eqs. (5) and (6), we have

$$
I_{\text {SERS }}=\alpha \exp \left\{-4 \kappa r \sin \left[\theta_{\infty}+\frac{1}{2} \exp \left(-\frac{\beta}{2} t\right)(\beta t+2)\left(\theta_{0}-\theta_{\infty}\right)\right]\right\},
$$

where $\alpha=I_{\text {Raman }} \frac{\left|E_{0}\left(\omega_{0}\right)\right|^{4}}{\left|E_{\text {inc }}\left(\omega_{0}\right)\right|^{4}}$ is variable for different Raman modes.

Up to now, the above mathematics illustrated the dependence of the SERS intensity $I_{S E R S}$ on the irradiation time $t$. After taking the right parameters into Eq. (7): $\theta_{0}=19 \pi / 60$ and $\theta_{\infty}=0$, the calculated results of the intensities of SERS peaks 
at $364,1078,1587 \mathrm{~cm}^{-1}$ are shown in Fig. $7 \mathrm{~b}$ (solid lines), respectively. It clearly displays good agreement of the calculated results and experiment data.

\section{Data availability}

All the data that support the findings of this study are available within the paper and its Supplementary Information files or from the corresponding author upon reasonable request. The source data underlying Figs. $2 \mathrm{a}-\mathrm{c}, 3 \mathrm{a}, \mathrm{b}$, and $6 \mathrm{~b}$ are provided as a Source Data file.

\section{Code availability}

All relevant code is available upon request from the corresponding author.

Received: 22 August 2019; Accepted: 2 March 2020;

Published online: 14 April 2020

\section{References}

1. Fleischmann, M., Hendra, P. J. \& McQuillan, A. J. Raman spectra of pyridine adsorbed at a silver electrode. Chem. Phys. Lett. 26, 163-166 (1974).

2. Zhou, L. et al. Immunoassay for tumor markers in human serum based on $\mathrm{Si}$ nanoparticles and SiC@Ag SERS-active substrate. Analyst 141, 2534-2541 (2016).

3. Shalabaeva, V. et al. Time resolved and label free monitoring of extracellular metabolites by surface enhanced Raman spectroscopy. PLoS One 12, 0175581-0175596 (2017).

4. Shi, G. C. et al. Dragonfly wing decorated by gold nanoislands as flexible and stable substrates for surface-enhanced Raman scattering (SERS). Sci. Rep. 8, 6916-6926 (2018).

5. Dasary, S. S. R., Singh, A. K., Senapati, D., Yu, H. \& Ray, P. C. Gold nanoparticle based label-free SERS probe for ultrasensitive and selective detection of trinitrotoluene. J. Am. Chem. Soc. 131, 13806-13812 (2009).

6. Schatz, G. C., Young, M. A. \& Van Duyne, R. P. In Surface-Enhanced Raman Scattering: Physics and Applications (eds Kneipp, K., Moskovits, M., \& Kneipp, H.) (Springer Berlin Heidelberg, 2006).

7. Jensen, L., Aikens, C. M. \& Schatz, G. C. Electronic structure methods for studying surface-enhanced Raman scattering. Chem. Soc. Rev. 37, 1061-1073 (2008).

8. Kelly, K. L., Coronado, E., Zhao, L. L. \& Schatz, G. C. The optical properties of metal nanoparticles: the influence of size, shape, and dielectric environment. $J$. Phys. Chem. B 107, 668-677 (2003).

9. Ding, S.-Y. et al. Nanostructure-based plasmon-enhanced Raman spectroscopy for surface analysis of materials. Nat. Rev. Mater. 1, 16021-16036 (2016)

10. Adrian, F. J. Charge transfer effects in surface-enhanced Raman scattering. J. Chem. Phys. 77, 5302-5314 (1982).

11. Otto, A. The 'chemical' (electronic) contribution to surface-enhanced Raman scattering. J. Raman. Spectrosc. 36, 497-509 (2005)

12. Tognalli, N. G. et al. From single to multiple Ag-layer modification of Au nanocavity substrates: a tunable probe of the chemical surface-enhanced raman scattering mechanism. ACS Nano. 5, 5433-5443 (2011).

13. Sharma, B., Frontiera, R. R., Henry, A.-I., Ringe, E. \& Van Duyne, R. P. SERS: Materials, applications, and the future. Mater. Today 15, 16-25 (2012).

14. Cong, S. et al. Noble metal-comparable SERS enhancement from semiconducting metal oxides by making oxygen vacancies. Nat. Commun. 6, 7800-7806 (2015).

15. Lin, J. et al. Ultrasensitive SERS detection by defect engineering on single $\mathrm{Cu}_{2} \mathrm{O}$ superstructure particle. Adv. Mater. 29, 1604797-1604804 (2017)

16. Zheng, Z. et al. Semiconductor SERS enhancement enabled by oxygen incorporation. Nat. Commun. 8, 1993-2002 (2017).

17. Haldavnekar, R., Venkatakrishnan, K. \& Tan, B. Non plasmonic semiconductor quantum SERS probe as a pathway for in vitro cancer detection. Nat. Commun. 9, 3065-3082 (2018).

18. Lombardi, J. R., Birke, R. L., Lu, T. \& Xu, J. Charge-transfer theory of surface enhanced Raman spectroscopy: Herzberg-Teller contributions. J. Chem. Phys. 84, 4174-4180 (1986).

19. Lombardi, J. R. \& Birke, R. L. Theory of surface-enhanced Raman scattering in semiconductors. J. Phys. Chem. C. 118, 11120-11130 (2014).

20. Alessandri, I. \& Lombardi, J. R. Enhanced Raman scattering with dielectrics. Chem. Rev. 116, 14921-14981 (2016).

21. Prakash, J., Sun, S., Swart, H. C. \& Gupta, R. K. Noble metals-TiO nanocomposites: from fundamental mechanisms to photocatalysis, surface enhanced Raman scattering and antibacterial applications. Appl. Mater. Today 11, 82-135 (2018)
22. Guo, Y. et al. Fabrication of $\mathrm{Ag}-\mathrm{Cu}_{2} \mathrm{O} /$ reduced graphene oxide nanocomposites as surface-enhanced Raman scattering substrates for in situ monitoring of peroxidase-like catalytic reaction and biosensing. ACS Appl. Mater. Inter 9, 19074-19081 (2017)

23. Liu, L. et al. Au-ZnO hybrid nanoparticles exhibiting strong charge-transferinduced SERS for recyclable SERS-active substrates. Nanoscale 7, 5147-5151 (2015).

24. Yang, L. et al. Observation of enhanced Raman scattering for molecules adsorbed on $\mathrm{TiO}_{2}$ nanoparticles: charge-transfer contribution. J. Phys. Chem. C. 112, 20095-20098 (2008).

25. Yang, L. et al. Charge-transfer-induced surface-enhanced Raman scattering on Ag- $\mathrm{TiO}_{2}$ nanocomposites. J. Phys. Chem. C. 113, 16226-16231 (2009).

26. Ben-Jaber, S. et al. Photo-induced enhanced Raman spectroscopy for universal ultra-trace detection of explosives, pollutants and biomolecules. Nat. Commun. 7, 12189-12194 (2016)

27. Fromm, D. P. et al. Exploring the chemical enhancement for surface-enhanced Raman scattering with Au bowtie nanoantennas. J. Chem. Phys. 124, 061101-061104 (2006).

28. Kokaislová, A., Helešicová, T., Ončák, M. \& Matějka, P. Spectroscopic studies of folic acid adsorbed on various metal substrates: does the type of substrate play an essential role in temperature dependence of spectral features? J. Raman. Spectrosc. 45, 750-757 (2014)

29. Ho, C.-H. \& Lee, S. SERS and DFT investigation of the adsorption behavior of 4-mercaptobenzoic acid on silver colloids. Colloid Surf. A 474, 29-35 (2015).

30. Chen, J., Yang, H. B., Miao, J., Wang, H.-Y. \& Liu, B. Thermodynamically driven one-dimensional evolution of anatase $\mathrm{TiO}_{2}$ nanorods: one-step hydrothermal synthesis for emerging intrinsic superiority of dimensionality. J. Am. Chem. Soc. 136, 15310-15318 (2014).

31. Yang, L. et al. A Ag synchronously deposited and doped $\mathrm{TiO}_{2}$ hybrid as an ultrasensitive SERS substrate: a multifunctional platform for SERS detection and photocatalytic degradation. Phys. Chem. Chem. Phys. 20, 15149-15157 (2018).

32. Pham, T.-D. \& Lee, B.-K. Effects of Ag doping on the photocatalytic disinfection of E. coli in bioaerosol by $\mathrm{Ag}-\mathrm{TiO}_{2} / \mathrm{GF}$ under visible light. J. Colloid Interf. Sci. 428, 24-31 (2014).

33. Liu, R., Wang, P., Wang, X., Yu, H. \& Yu, J. UV- and visible-light photocatalytic activity of simultaneously deposited and doped $\mathrm{Ag} / \mathrm{Ag}(\mathrm{I})-\mathrm{TiO}_{2}$ photocatalyst. J. Phys. Chem. C. 116, 17721-17728 (2012).

34. Perreault, D. et al. Silver and gold dimers. Crystal and molecular structure of $\mathrm{Ag}_{2}(\mathrm{dmpm})_{2} \mathrm{Br}_{2}$ and $\left[\mathrm{Au}_{2}(\mathrm{dmpm})_{2}\right](\mathrm{PF} 6)_{2}$ and relation between metal-metal force constants and metal-metal separations. Inorg. Chem. 31, 695-702 (1992).

35. Leung, K. H., Phillips, D. L., Tse, M.-C., Che, C.-M. \& Miskowski, V. M. Resonance Raman investigation of the $\mathrm{Au}(\mathrm{I})-\mathrm{Au}(\mathrm{I})$ interaction of the 1 [d $\sigma^{*}$ p $\left.\sigma\right]$ excited state of $\mathrm{Au}_{2}(\mathrm{dcpm})_{2}\left(\mathrm{ClO}_{4}\right)_{2}(\mathrm{dcpm}=$ bis (dicyclohexylphosphine)methane). J. Am. Chem. Soc. 121, 4799-4803 (1999).

36. F., Z. W., L., H. Y., S., Z. M., Z., Y. \& Q., C. Raman scattering study on anatase $\mathrm{TiO}_{2}$ nanocrystals. J. Phys. D: Appl. Phys. 33, 912-916 (2000).

37. Ma, W.-q, Fang, Y., Hao, G.-1 \& Wang, W.-g Adsorption behaviors of 4mercaptobenzoic acid on silver and gold films. Chin. J. Chem. Phys. 23, 659-663 (2010).

38. Bishnoi, S. W. et al. All-optical nanoscale pH Meter. Nano Lett. 6, 1687-1692 (2006)

39. Yan, R. et al. Thermal conductivity of monolayer molybdenum disulfide obtained from temperature-dependent Raman spectroscopy. ACS Nano. 8, 986-993 (2014).

40. Canpean, V. \& Astilean, S. Temperature effect on the SERS signature of paminothiophenol: a new evidence for the production of $\mathrm{p}, \mathrm{p}$ '-dimercaptoazobenzene on metallic nanostructures. Spectrochim. Acta A. 96, 862-867 (2012)

41. Yang, K.-H., Liu, Y.-C. \& Yu, C.-C. Effects of substrate temperatures on improved surface-enhanced Raman scattering. Electrochim. Acta 54, 4202-4207 (2009)

42. Yang, K.-H., Liu, Y.-C. \& Hsu, T.-C. Interesting substrate-temperature dependence on surface-enhanced Raman scattering. J. Electroanal. Chem. 632, 184-191 (2009)

43. Redmond, G., O’Keeffe, A., Burgess, C., MacHale, C. \& Fitzmaurice, D. Spectroscopic determination of the flatband potential of transparent nanocrystalline zinc oxide films. J. Phys. Chem. 97, 11081-11086 (1993).

44. Ji, W. et al. pH-dependent SERS by semiconductor-controlled charge-transfer contribution. J. Phys. Chem. C. 116, 24829-24836 (2012).

45. Li, S., Ye, G. \& Chen, G. Low-temperature preparation and characterization of nanocrystalline anatase $\mathrm{TiO}_{2}$. J. Phys. Chem. C. 113, 4031-4037 (2009).

46. Braun, A. et al. Observation of substrate orientation-dependent oxygen defect filling in thin $\mathrm{WO}_{3}-\delta / \mathrm{TiO}_{2}$ pulsed laser-deposited films with in situ XPS at high oxygen pressure and temperature. Chem. Mater. 24, 3473-3480 (2012).

47. Nan, H. et al. Strong photoluminescence enhancement of $\mathrm{MoS}_{2}$ through defect engineering and oxygen bonding. ACS Nano 8, 5738-5745 (2014). 
48. Zhang, J., Li, M., Feng, Z., Chen, J. \& Li, C. UV Raman spectroscopic study on $\mathrm{TiO}_{2}$. I. Phase transformation at the surface and in the bulk. J. Phys. Chem. B 110, 927-935 (2006).

49. Lombardi, J. R. \& Birke, R. L. A unified approach to surface-enhanced Raman spectroscopy. J. Phys. Chem. C. 112, 5605-5617 (2008).

50. Tarakeshwar, P. et al. SERS as a probe of charge-transfer pathways in hybrid dye/molecule-metal oxide complexes. J. Phys. Chem. C. 118, 3774-3782 (2014).

51. Tunc, I., Bruns, M., Gliemann, H., Grunze, M. \& Koelsch, P. Bandgap determination and charge separation in $\mathrm{Ag} @ \mathrm{TiO}_{2}$ core shell nanoparticle films. Surf. Interface Anal. 42, 835-841 (2010).

52. Li, P. et al. Investigation of charge-transfer between a 4-mercaptobenzoic acid monolayer and $\mathrm{TiO}_{2}$ nanoparticles under high pressure using surfaceenhanced Raman scattering. Chem. Commun. 54, 6280-6283 (2018).

53. Calandra, P., Lombardo, D., Pistone, A., Turco Liveri, V. \& Trusso, S. Structural and optical properties of novel surfactant-coated ${\mathrm{Yb} @ \mathrm{TiO}_{2}}$ nanoparticles. J. Nanopart. Res. 13, 5833-5839 (2010).

54. Zhang, X. et al. Charge-transfer effect on surface-enhanced Raman scattering (SERS) in an ordered Ag NPs/4-mercaptobenzoic Acid/TiO 2 system. J. Phys. Chem. C. 119, 22439-22444 (2015).

55. Wang, X. et al. Two-dimensional amorphous $\mathrm{TiO}_{2}$ nanosheets enabling highefficiency photoinduced charge transfer for excellent SERS activity. J. Am. Chem. Soc. 141, 5856-5862 (2019).

56. Ma, N. et al. New insight into charge-transfer enhancement for SERS in cosputtering $(\mathrm{Ag}) \mathrm{x}(\mathrm{ZnS}) \mathrm{y}$ system: the carrier density effect. J. Phys. Chem. C. 123, 28846-28851 (2019).

57. Wen, B. Y. et al. Shell-isolated nanoparticle-enhanced Raman spectroscopy study of the adsorption behaviour of DNA bases on $\mathrm{Au}(111)$ electrode surfaces. Analyst 141, 3731-3736 (2016).

58. Martin Sabanes, N., Ohto, T., Andrienko, D., Nagata, Y. \& Domke, K. F. Electrochemical TERS elucidates potential-induced molecular reorientation of adenine/Au(111). Angew. Chem. Int. Ed. 56, 9796-9801 (2017).

59. Uetsuki, K. et al. Experimental identification of chemical effects in surface enhanced Raman scattering of 4-aminothiophenol. J. Phys. Chem. C. 114, 7515-7520 (2010).

60. Lu, G., Shrestha, B. \& Haes, A. J. Importance of tilt angles of adsorbed aromatic molecules on nanoparticle rattle SERS substrates. J. Phys. Chem. C. 120, 20759-20767 (2016)

61. Pelton, M. \& Bryant, G. W. Introduction to metal-nanoparticle plasmonics. (John Wiley \& Sons 2013).

62. Yamamoto, Y. S., Ozaki, Y. \& Itoh, T. Recent progress and frontiers in the electromagnetic mechanism of surface-enhanced Raman scattering. J. Photoch. Photobio. C. 21, 81-104 (2014).

63. Yoshida, K.-i et al. Quantitative evaluation of electromagnetic enhancement in surface-enhanced resonance Raman scattering from plasmonic properties and morphologies of individual Ag nanostructures. Phys. Rev. B 81, 115406-115414 (2010).

64. Le, Ru,E. \& Etchegoin, P. Principles of Surface-Enhanced Raman Spectroscopy: and related plasmonic effects. (Elsevier, Amsterdam, 2009).

65. García-Vidal, F. J. \& Pendry, J. B. Collective theory for surface enhanced Raman scattering. Phys. Rev. Lett. 77, 1163-1166 (1996).

\section{Acknowledgements}

This work was supported by the National Natural Science Foundation of China (Grant Nos. 61320106014 and 61675104) and K.C. Wong Magna Fund in Ningbo University, China. And the authors thank to Prof Yi Luo (USTC), Dr Qiang Wu (Northumbria University), Dr Jian Wu (NUDT), Dr Zhufeng Zhang, and Dr Shiwei Tang (Ningbo University) for fruitful discussions; thank to Prof Laihui Luo, Dr Shuiping Huang, and Dr Changgui Lin (Ningbo University) for the experimental helps; thank to NIMTE, CAS for the assistance provided in the measurements of substrate samples.

\section{Author contributions}

J.Z. proposed and designed the project, analyzed the experimental data, revised and determined the manuscript; L.Z. performed the material synthesis, characterization, Raman measurement, wrote and revised the manuscript; W.L. performed the initial experiments and revised the final manuscript; X.Y. and J.M. performed theoretical calculations; L.S. provided the key experimental helps; C.G. contributed to the data interpretation; T.J., E.Y.B.P., L.S., and L.P. assisted in evaluating the results and revising the manuscript; X.S., Z.J., Q.L., J.H., and P.M. participated in the discussion and commented on the manuscript.

\section{Competing interests}

The authors declare no competing interests.

\section{Additional information}

Supplementary information is available for this paper at https://doi.org/10.1038/s41467020-15484-6.

Correspondence and requests for materials should be addressed to J.Z.

Peer review information Nature Communications thanks Dmitry Kurouski and the other, anonymous reviewer(s) for their contribution to the peer review of this work.

Reprints and permission information is available at http://www.nature.com/reprints

Publisher's note Springer Nature remains neutral with regard to jurisdictional claims in published maps and institutional affiliations.

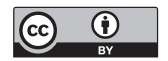

Open Access This article is licensed under a Creative Commons Attribution 4.0 International License, which permits use, sharing, adaptation, distribution and reproduction in any medium or format, as long as you give appropriate credit to the original author(s) and the source, provide a link to the Creative Commons license, and indicate if changes were made. The images or other third party material in this article are included in the article's Creative Commons license, unless indicated otherwise in a credit line to the material. If material is not included in the article's Creative Commons license and your intended use is not permitted by statutory regulation or exceeds the permitted use, you will need to obtain permission directly from the copyright holder. To view a copy of this license, visit http://creativecommons.org/licenses/by/4.0/.

(c) The Author(s) 2020 